\title{
RUMIAS PERFECCIONISTAS EN FUNCIÓN DE LA VIVEZA DE IMÁGENES MENTALES VISUALES
}

\author{
Ma Pilar Aparicio Flores \\ Universidad de Alicante \\ pilar.aparicio@ua.es \\ Ricardo Sanmartín López \\ Universidad de Alicante \\ ricardo.sanmartin@ua.es \\ María Vicent Juan \\ Universidad de Alicante \\ maria.vicent@ua.es
}

Recepción Artículo: 27 octubre 2021 Admisión Evaluación: 27 octubre 2021 Informe Evaluador 1: 28 octubre 2021 Informe Evaluador 2: 29 octubre 2021 Aprobación Publicación: 30 octubre 2021

\section{RESUMEN}

El estudio de los Pensamientos Automáticos Perfeccionistas (PAP) está en auge tras observar su efecto negativo sobre la salud de las personas. De ahí la necesidad de buscar estrategias de prevención de estas rumias de perfección. El objetivo del estudio fue observar si existen diferencias estadísticamente significativas en las dimensiones de la vivacidad o capacidad de imagen mental (CIM) en función de las altas o bajas puntuaciones de los distintos factores de PAP, así como analizar la probabilidad de presentar PAP en función de los factores de CIM. Para ello se reclutó una muestra de 791 universitarios españoles $(M=22.5 ; D E=5.21)$ y se utilizó la Perfectionism Cognitions Inventory (PCl) y la Vividness Visual Imagery Questionnaire-Revised Version 12 (VVIQRV-12). Los resultados arrojan diferencias estadísticamente significativas en la Capacidad Creativa de Imágenes (CCI) en todos los factores, puntuando más alto en función de los bajos Esfuerzos (EP; $d=32$ ) y Demandas Perfeccionistas (DP; $d=.22)$; sugiriendo, además, que a medida que aumenta la CCI disminuye la probabilidad de presentar EP y DP. En conclusión, los hallazgos del estudio muestran características concretas de los PAP que benefician el diseño de estrategias de prevención sobre estas rumias poco saludables.

Palabras clave: pensamientos automáticos perfeccionistas; perfeccionismo; capacidad de imagen mental; nitidez; rumias

\section{ABSTRACT}

Perfectionist automatic thoughts and vivacity of mental image in Spanish undergraduates. The study of Perfectionist Automatic Thoughts (PAT) is booming after observing its negative effect on people's 


\section{RUMIAS PERFECCIONISTAS EN FUNCIÓN DE LA VIVEZA DE IMÁGENES MENTALES VISUALES}

health. Hence the need to seek prevention strategies for these rumors of perfection. The objective of the study was to observe whether there are statistically significant differences in the dimensions of vivacity or mental image capacity (MIC) based on the high or low scores of the different PAT factors, as well as to analyze the probability of presenting PAT based on of the MIC factors. For this, a sample of 791 Spanish university students $(M=22.5$; $S D=5.21)$ was recruited and the Perfectionism Cognitions Inventory $(\mathrm{PCl})$ and the Vividness Visual Imagery Questionnaire-Revised Version 12 (VVIQ-RV-12) were used. The results show statistically significant differences in the Creative Capacity of Images $(\mathrm{CCl})$ in all the factors, scoring higher according to the low Strivings (PS; $d=$ .32) and Perfectionist Demands (PD; $d=.22)$; suggesting, in addition, that as CCI increases, the probability of presenting PS and PD decreases. In conclusion, the study findings show specific characteristics of PATs that benefit the design of prevention strategies on these unhealthy rumors.

Keywords: perfectionist automatic thoughts; perfectionism; mental image capacity; clarity; rumination

\section{INTRODUCCIÓN}

El perfeccionismo es un rasgo de la personalidad que afecta de modo negativo en la vida diaria de las personas que lo sufren (Babapour et al., 2015). Este rasgo complejo se determina por la exigencia de estándares fuera de la realidad y por un constante y desmedido sacrificio personal encaminado al alcance de un alto rendimiento (Crãciun y Holdevici, 2012).

Diversas investigaciones confirman, en la persona perfeccionista, el posible desencadenamiento de sentimientos de nulidad, nerviosismo (Smith et al., 2016), desgaste mental (Mahmoodi-Shahrebabaki, 2017), estrés (Flett et al., 2016), ansiedad social (Esteve-Faubel et al., 2020), dificultades interpersonales (Aparicio-Flores, Vicent et al., 2020) e incluso una rumia psicológica constante derivada de pensamientos perfeccionistas (Flett et al., 2011). En este sentido, se encuentran los Pensamientos Automáticos Perfeccionistas (PAP), conocidos como rumias que reflejan la necesidad de ser perfecto y/o la preocupación de no cometer ninguna imperfección en público (Flett et al., 1998). Este tipo de reflexiones revelan un alto nivel de angustia debido a su pensamiento constante y divergente entre lo que es el "yo real" y el "yo ideal" (Hewitt y Genest, 1990), ya que esa preocupación rumiante se prolonga en el tiempo, lo que eleva el nivel de estrés del sujeto (Flett et al., 2016) y malestar personal (Aparicio-Flores et al., 2021), con un descenso de la creatividad (Bass et al., 2014) y de la viveza o capacidad de imágenes mentales (CIM; Aparicio-Flores, 2020).

No obstante, y aunque en menor proporción, diversas investigaciones afirman que algunos rasgos perfeccionistas también se asocian con medidas de ajuste y adaptación entre los que destacan autorregulación (Shih, 2011), rendimiento académico (Damian et al., 2017) y creatividad (Wigert et al., 2012). De ahí que su interpretación acarrea un profundo debate entre quienes amparan una esencia adaptativa y otra desadaptativa del perfeccionismo.

Por lo que respecta a su carácter adaptativo, son pocos los estudios que trabajen variables perfeccionistas y su relación con la imaginería mental. Sin embargo, investigaciones anteriores como la de Tapia-Pavón (2012) afirma que sujetos perfeccionistas, entre los que destacan científicos, deportistas de élite, músicos y artistas, obtienen los mayores logros de rendimiento.

\section{OBJETIVOS DE LA INVESTIGACIÓN}

El objetivo del estudio es analizar el vínculo entre la CIM y los PAP en universitarios españoles. Concretamente, los objetivos específicos del trabajo se concretan en: a) observar si existen diferencias estadísticamente significativas en los factores de la CIM y las dimensiones de PAP; y b) analizar la probabilidad de aumento de la CIM sobre el aumento de los PAP.

\section{MUESTRA Y/O PARTICIPANTES}

La muestra se fue compuesta por 791 universitarios de la Universidad de Alicante, con edades comprendidas entre 19 y $24(M=22.5 ; D E=5.21)$. Los estudiantes cursaban $4^{\circ}$ curso del Grado universitario en maestro de Educación Infantil o Educación Primaria. Un total del 68\% eran mujeres. 


\section{METODOLOGÍA Y/O INSTRUMENTOS UTILIZADOS}

\section{Instrumentos}

Perfectionism Cognitions Inventory (PCl; Flett et al., 1998): La versión española del PCl (Esteve-Faubel et al., 2020) se trata de una versión multidimensional del PCl original diseñado y validado por Flett et al. (1998). Esta versión se compone de 17 ítems con 5 opciones de respuesta ( 1 = De ningún modo; 5 = Todo el tiempo) y tres factores: Fl. Preocupaciones Perfeccionistas (PP), con 6 ítems, que miden preocupaciones sobre la realización de una tarea y la ansiedad de no alcanzar el rendimiento deseado (ej.: ¿Por qué no puedo ser perfecto?); Fll. Demandas Perfeccionistas (DP), con 4 ítems, que evalúan pensamientos de auto-mejora (ej.: Debería estar haciendo más); Flll. Esfuerzos Perfeccionistas (EP), con 7 ítems, que miden los juicios sobre el sacrificio excesivo para lograr la perfección (ej.: Siempre puedo hacerlo mejor, incluso si las cosas son casi perfectas).

Las propiedades psicométricas de la escala fueron aceptables para todas sus dimensiones, así como para el total de la escala ( $\alpha=.71, .86, .88$ y .83, respectivamente).

Vividness Visual Imagery Questionnaire-Revised Version-12 (VVIQ-RV-12; Aparicio-Flores, Esteve-Faubel et al., 2020): La VVIQ-RV-12 es la versión española del VVIQ diseñado y validado por Marks (1973) para evaluar la CIM.

Esta nueva versión cuenta con 12 ítems y se compone de 4 distintos factores: Fl.: Imágenes Espaciales en Movimiento (IEM), con 3 ítems, que evalúan las imágenes climáticas en movimiento creadas a través del recuerdo (ej.: Las nubes. Cae una gran tormenta junto con destellos de relámpagos); Fll.: Imágenes Familiares (IF), con 3 ítems, que mide la capacidad de nitidez sobre el recuerdo de imágenes en movimiento de familiares (ej.: Los movimientos característicos de la cabeza, las actitudes del cuerpo, etc.); Flll: Recuerdo de Objetos Detallados (ROD), con 3 ítems, que evalúan el recuerdo nítido de lugares que se frecuentan de manera asidua (ej.: Un escaparate, con los colores, formas y detalles de Ios productos expuestos); y FIV. Capacidad Creativa de Imágenes (CCI), con 3 ítems, que miden la nitidez de imágenes de lugares no frecuentados anteriormente (ej.: Piense en una escena campestre en la que haya árboles, montañas y un lago. Evalúe: el color y la forma de los árboles).

Las propiedades psicométricas de la escala fueron aceptables para todos sus factores, así como para el total de la escala ( $\alpha=.82, .72, .75$ y .82, respectivamente).

\section{Procedimiento}

Se realizó una entrevista con el profesorado encargado de la docencia de los estudiantes entrevistados, con el fin de informarles de la finalidad del estudio y solicitar su colaboración. Seguidamente, se administraron los cuestionarios en alrededor de 30 minutos, advirtiendo del proceso voluntario y anónimo y solicitando su consentimiento informado. En el proceso se contó con la presencia de uno de los investigadores y con el profesorado encargado.

\section{Análisis de datos}

Los análisis de datos para evaluar la significatividad de las diversas variables fueron realizados mediante el índice $d$, y analizados bajo los criterios propuestos por Cohen (1988), el cual estima un tamaño del efecto pequeño entre .20 y .49 , moderado entre .50 y .79 , y grande mayor que .80 .

La probabilidad predictiva se analizó mediante regresión logística con el procedimiento de pasos hacia adelante basado en el estadístico de Wald, estimada bajo el estadístico odd ratio (OR).

La $R^{2}$ de Nagelkerke, informa del porcentaje de varianza explicada por el modelo (Nagelkerke, 1991), y el de casos clasificados correctamente. Por último, la variable dependiente se dicotomizó en bajas (centil <25) y altas puntuaciones (centil >75). 


\section{RUMIAS PERFECCIONISTAS EN FUNCIÓN DE LA VIVEZA DE IMÁGENES MENTALES VISUALES}

\section{RESULTADOS ALCANZADOS}

\section{Diferencias en CIM con altas y bajas puntuaciones en PP}

La Tabla 1 y Figura 1 muestran las medias y diferencias estadísticamente significativas observadas en la CIM desde universitarios con altas y bajas puntuaciones en PP (Factor I del PCI).

Los hallazgos arrojan diferencias estadísticamente significativas tanto en Imágenes Espaciales en Movimiento ( $d=.25$ ) como en Recuerdo de Objetos Detallados ( $d=.21$ ) con una baja magnitud en ambos factores del VVIQ-RV-12.

Se observa que los universitarios con elevadas puntuaciones en PP puntúan significativamente más alto tanto en Imágenes Espaciales en Movimiento como en Recuerdo de Objetos Detallados que los universitarios con bajas puntuaciones en PP.

Tabla 1.Diferencias en CIM con altas y bajas puntuaciones en PP

\begin{tabular}{cccc}
\hline Prueba de & Bajas & Altas & Significación \\
Levene & puntuaciones & puntuaciones & Estadística
\end{tabular}

\begin{tabular}{|c|c|c|c|c|c|c|c|c|c|c|}
\hline Dimensiones & $F$ & $p$ & $M$ & DT & $M$ & $D T$ & $t$ & g.l & $p$ & $d$ \\
\hline IEM & 1.85 & $\begin{array}{r}.17 \\
4 \\
\end{array}$ & 5.21 & $\begin{array}{r}2.4 \\
5 \\
\end{array}$ & 5.85 & $\begin{array}{r}2.7 \\
0 \\
\end{array}$ & -2.40 & 388 & $\begin{array}{r}.01 \\
7 \\
\end{array}$ & .25 \\
\hline IF & 1.10 & $\begin{array}{r}.29 \\
3 \\
\end{array}$ & 8.32 & $\begin{array}{r}3.4 \\
4 \\
\end{array}$ & 7.94 & $\begin{array}{r}3.2 \\
8 \\
\end{array}$ & 1.10 & 388 & $\begin{array}{r}.27 \\
1 \\
\end{array}$ & - \\
\hline ROD & 1.65 & $\begin{array}{r}.19 \\
9\end{array}$ & 5.80 & $\begin{array}{r}2.4 \\
3\end{array}$ & 6.31 & $\begin{array}{r}2.5 \\
1\end{array}$ & -1.98 & 388 & $\begin{array}{r}.04 \\
8\end{array}$ & .21 \\
\hline $\mathrm{CCI}$ & .18 & $\begin{array}{r}.66 \\
6 \\
\end{array}$ & 5.92 & $\begin{array}{r}2.3 \\
2 \\
\end{array}$ & 6.24 & $\begin{array}{r}2.3 \\
2 \\
\end{array}$ & -1.31 & 388 & $\begin{array}{r}.19 \\
0 \\
\end{array}$ & - \\
\hline $\begin{array}{l}\text { Total } \\
\text { VVIQ-RV- } \\
12\end{array}$ & .35 & $\begin{array}{r}.55 \\
4\end{array}$ & 25.27 & $\begin{array}{r}7.3 \\
1\end{array}$ & 26.35 & $\begin{array}{r}7.3 \\
9\end{array}$ & -1.43 & 388 & $\begin{array}{r}.15 \\
3\end{array}$ & - \\
\hline
\end{tabular}

*Nota: IEM = Imágenes Espaciales en Movimiento; IF = Imágenes Familiares; ROD = Recuerdo de Objetos Detallados; CCI = Capacidad Creativa de Imágenes

Figura 1. Diferencias en CIM en universitarios con altas y bajas puntuaciones en $P P^{\star}{ }^{\star} p<.05,{ }^{\star \star} p<.01,{ }^{\star \star \star}{ }^{*} p<.001$

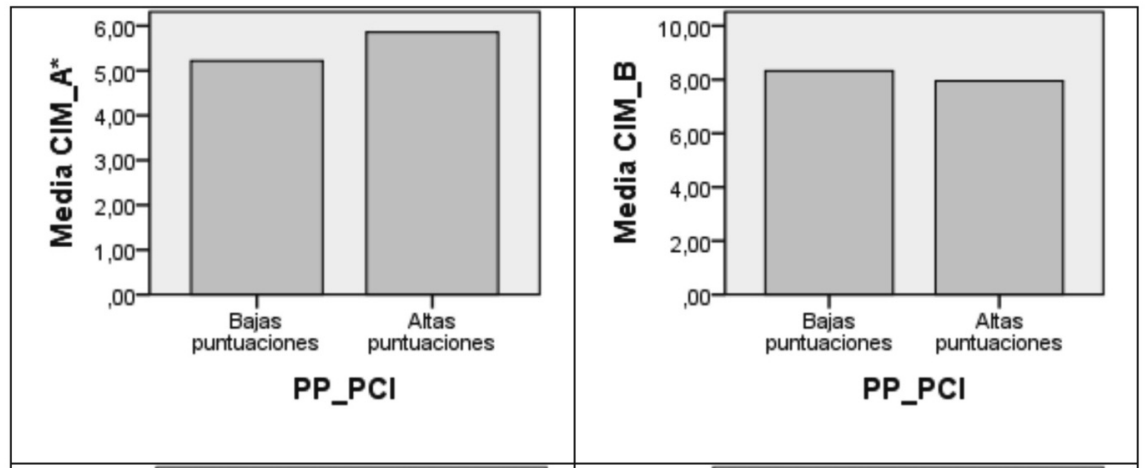



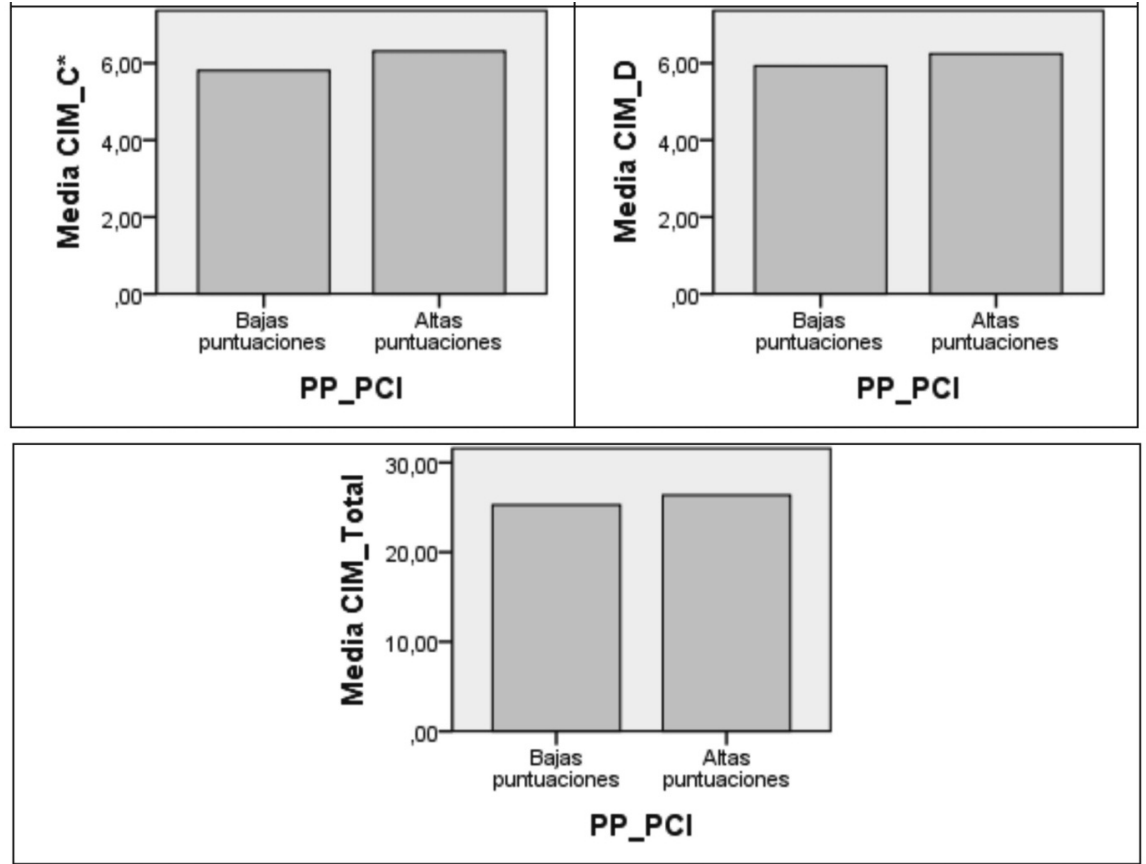

\section{Regresión logística binaria para la probabilidad de presentar alta puntuación en PP en función de las Imágenes Espaciales en Movimiento y el Recuerdo de Objetos Detallados}

Los hallazgos permiten hacer una estimación correcta del $57.4 \%$ de los casos $\left(\chi^{2}=5.84 ; p=<.05\right)$ para las Imágenes Espaciales en Movimiento y del $57.4 \%$ de los casos $\left(\chi^{2}=3.97 ; p=<.05\right)$ para el Recuerdo de Objetos Detallados. El valor de ajuste de los modelos fue de .02 para las Imágenes Espaciales en Movimiento y del .01 para el Recuerdo de Objetos Detallados (véase Tabla 2).

Los valores de la odd ratio $(O R)$ fueron > 1 señalando que a medida que aumenta la puntuación en Imágenes Espaciales en Movimiento y Recuerdo de Objetos Detallados aumenta la posibilidad de presentar elevadas puntuaciones en PP. Los valores obtenidos fueron 1.10 en Imágenes Espaciales en Movimiento y 1.08 en Recuerdo de Objetos Detallados.

Tabla 2. Regresión logística binaria para la probabilidad de presentar alto PP en función de las variables Imágenes Espaciales en Movimiento y Recuerdo de Objetos Detallados

\begin{tabular}{|c|c|c|c|c|c|c|c|c|c|}
\hline $\begin{array}{c}\text { Variab } \\
\text { le }\end{array}$ & & $\chi^{2}$ & $R^{2}$ & $B$ & E.T. & Wald & $p$ & $O R$ & I.C. $95 \%$ \\
\hline \multirow[t]{2}{*}{ IEM } & $\begin{array}{l}\text { Clasificados } \\
\text { correc.: } 57.4 \%\end{array}$ & 5.84 & .02 & .09 & .04 & 5.62 & .018 & 1.10 & \multirow[t]{2}{*}{$1,02-1.20$} \\
\hline & Constante & & & -.23 & .24 & .92 & .336 & .78 & \\
\hline \multirow[t]{2}{*}{ ROD } & $\begin{array}{l}\text { Clasificados } \\
\text { correc.: } 57.4 \%\end{array}$ & 3.97 & .01 & .08 & .04 & 3.88 & .049 & 1.08 & \multirow[t]{2}{*}{$1.01-1.18$} \\
\hline & Constante & & & -.20 & .27 & .55 & .456 & .81 & \\
\hline
\end{tabular}

*Nota: $\chi^{2}=$ Chi cuadrado; $R^{2}=$ Cuadrado de Nagelkerke; $B=$ Coeficiente de regresión; E.T.= Error estándar; Wald $=$ Prueba de Wald; $p=$ Probabilidad; $O R=$ Odd ratio; $I . C$. = Intervalo de confianza al 95\%; IEM = Imágenes Espaciales en Movimiento; IF = Imágenes Familiares; ROD = Recuerdo de Objetos Detallados. 


\section{Diferencias en CIM con altas y bajas puntuaciones en DP}

La Tabla 3 y Figura 2 muestran las medias y diferencias estadísticamente significativas en Recuerdo de Objetos Detallados, Capacidad Creativa de Imágenes y el total del VVIQ-RV-12 en universitarios con altas y bajas puntuaciones en DP.

Los resultados muestran diferencias significativas de baja magnitud para el Recuerdo de Objetos Detallados $(d=.22)$ y la Capacidad Creativa de Imágenes $(d=.22)$, lo que sugiere que los universitarios con bajas puntuaciones en DP puntúan significativamente más alto en Recuerdo de Objetos Detallados y Capacidad Creativa de Imágenes.

Tabla 3.Diferencias en CIM con altas y bajas puntuaciones en DP

\begin{tabular}{|c|c|c|c|c|c|c|c|c|c|c|}
\hline \multirow[b]{2}{*}{$\begin{array}{l}\text { Dimensione } \\
s\end{array}$} & \multicolumn{2}{|c|}{$\begin{array}{l}\text { Prueba de } \\
\text { Levene }\end{array}$} & \multicolumn{2}{|c|}{$\begin{array}{c}\text { Bajas } \\
\text { puntuaciones }\end{array}$} & \multicolumn{2}{|c|}{$\begin{array}{c}\text { Altas } \\
\text { puntuaciones }\end{array}$} & \multicolumn{4}{|c|}{$\begin{array}{l}\text { Significación } \\
\text { Estadística }\end{array}$} \\
\hline & $F$ & $p$ & $M$ & $D T$ & $M$ & $D T$ & $t$ & g.l & $p$ & $d$ \\
\hline IEM & 9.90 & $\begin{array}{r}.00 \\
2 \\
\end{array}$ & 5.96 & $\begin{array}{r}3.0 \\
4\end{array}$ & 5.45 & $\begin{array}{r}2.4 \\
7 \\
\end{array}$ & 1.77 & $\begin{array}{r}275.1 \\
2 \\
\end{array}$ & .077 & - \\
\hline IF & 7.32 & $\begin{array}{r}.00 \\
7 \\
\end{array}$ & 8.23 & $\begin{array}{r}3.0 \\
5 \\
\end{array}$ & 8.20 & $\begin{array}{r}3.6 \\
4 \\
\end{array}$ & .07 & $\begin{array}{r}370.7 \\
6 \\
\end{array}$ & .941 & - \\
\hline ROD & .03 & $\begin{array}{r}85 \\
9 \\
\end{array}$ & 6.25 & $\begin{array}{r}2.4 \\
3 \\
\end{array}$ & 5.74 & $\begin{array}{r}2.3 \\
3 \\
\end{array}$ & 2.12 & 416 & .035 & .22 \\
\hline $\mathrm{CCI}$ & .33 & $\begin{array}{r}.56 \\
5 \\
\end{array}$ & 6.56 & $\begin{array}{r}2.4 \\
7 \\
\end{array}$ & 6.02 & $\begin{array}{r}2.4 \\
8 \\
\end{array}$ & 2.15 & 416 & .032 & .22 \\
\hline $\begin{array}{l}\text { Total } \\
\text { VVIQ- } \\
\text { RV-12 }\end{array}$ & .01 & $\begin{array}{r}.91 \\
7\end{array}$ & $\begin{array}{r}27.0 \\
1\end{array}$ & $\begin{array}{r}7.5 \\
4\end{array}$ & $\begin{array}{r}25.4 \\
2\end{array}$ & $\begin{array}{r}7.3 \\
2\end{array}$ & 2.11 & 416 & .035 & .21 \\
\hline
\end{tabular}

*Nota: IEM = Imágenes Espaciales en Movimiento; IF = Imágenes Familiares; ROD = Recuerdo de Objetos Detallados; CCI = Capacidad Creativa de Imágenes

Figura 2. Diferencias en CIM en universitarios con altas y bajas puntuaciones en $D P .{ }^{\star} p<.05,{ }^{\star *} p<.01,{ }^{* \star *} p<.001$

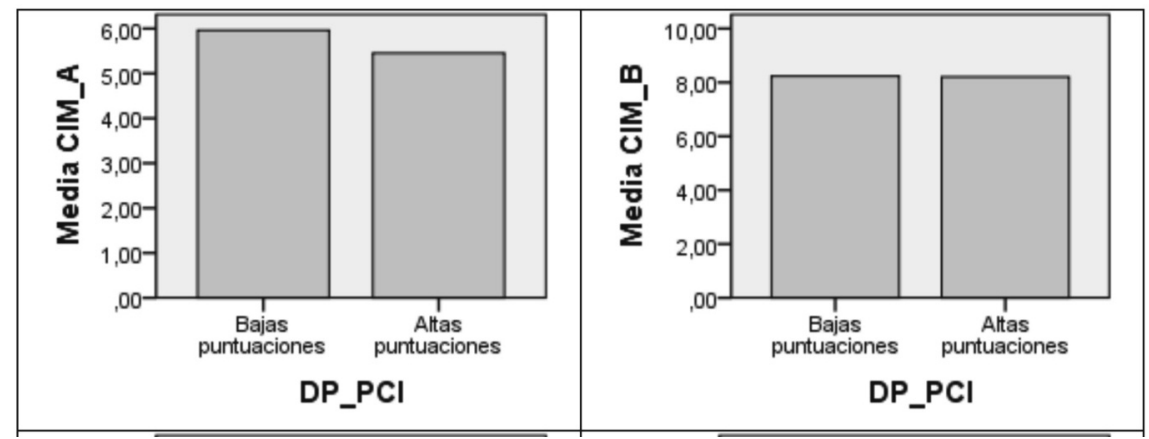



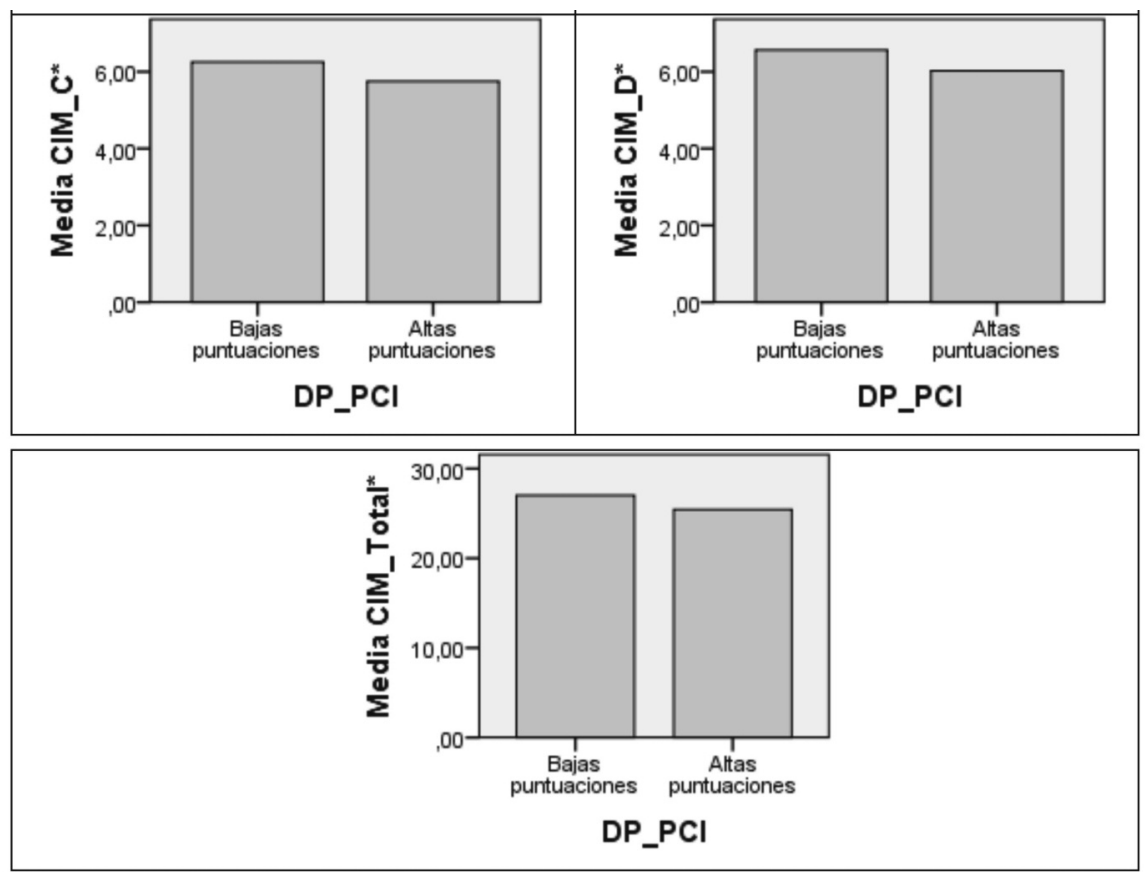

Regresión logística binaria para la probabilidad de presentar alta puntuación en DP en función de Recuerdo de Objetos Detallados y Capacidad Creativa de Imágenes

Los hallazgos permiten realizar una estimación correcta del $63.6 \%$ de los casos $\left(\chi^{2}=4.64 ; p=<.05\right)$ para el Recuerdo de Objetos Detallados, del $61.7 \%$ de los $\operatorname{casos}\left(\chi^{2}=4.60 ; p=<.05\right)$ para la Capacidad Creativa de Imágenes y del $63.2 \% \%$ para el total del VVIQ-RV-12 $\left(\chi^{2}=4.45 ; p=<.05\right)$. Asimismo, el valor de ajuste de los modelos ( $R^{2}$ Nagelkerke) es de 02 para la Capacidad Creativa de Imágenes y el total de la escala (véase Tabla 4).

Los valores de la odd ratio $(O R)$ fueron $<1$ sugiriendo que conforme aumenta la puntuación en Capacidad Creativa de Imágenes y el total del VVIQ-RV-12 disminuye la probabilidad de presentar altas puntuaciones en DP, con valores de .91 para el Recuerdo de Objetos Detallados y Capacidad Creativa de Imágenes y .97 para el total de la escala. 


\section{RUMIAS PERFECCIONISTAS EN FUNCIÓN DE LA VIVEZA DE IMÁGENES MENTALES VISUALES}

Tabla 4.Regresión logística binaria para la probabilidad de presentar alto DP en función de las variables Recuerdo de Objetos Detallados y Capacidad Creativa de Imágenes

\begin{tabular}{|c|c|c|c|c|c|c|c|c|c|}
\hline Variable & & $\chi^{2}$ & $R^{2}$ & $B$ & E.T. & Wald & $p$ & $O R$ & I.C. $95 \%$ \\
\hline \multirow[t]{2}{*}{ ROD } & $\begin{array}{l}\text { Clasificados } \\
\text { correc.: } \\
63.6 \%\end{array}$ & 4.64 & .03 & .08 & .04 & 4.42 & .035 & .91 & \multirow[t]{2}{*}{$.84-.99$} \\
\hline & Constante & & & 1,05 & .27 & $\begin{array}{r}14.5 \\
4 \\
\end{array}$ & $\begin{array}{r}<.00 \\
1 \\
\end{array}$ & 2.87 & \\
\hline \multirow[t]{2}{*}{$\mathrm{CCI}$} & $\begin{array}{l}\text { Clasificados } \\
\text { correc.: } \\
61.7 \%\end{array}$ & 4.60 & .02 & .08 & .04 & 4.56 & .033 & .91 & \multirow[t]{2}{*}{$.84-.99$} \\
\hline & Constante & & & 1,06 & .27 & $\begin{array}{r}14.7 \\
2 \\
\end{array}$ & $\begin{array}{r}<.00 \\
1 \\
\end{array}$ & 2.90 & \\
\hline \multirow[t]{2}{*}{$\begin{array}{l}\text { Total } \\
\text { VVIQ-RV- } \\
12\end{array}$} & $\begin{array}{l}\text { Clasificados } \\
\text { correc.: } \\
63.2 \%\end{array}$ & 4.45 & .02 & $0 \overline{2}$ & .01 & 4.40 & .036 & .97 & \multirow[t]{2}{*}{$.95-.99$} \\
\hline & Constante & & & 1,27 & .37 & $\begin{array}{r}11.4 \\
6\end{array}$ & .001 & 3.57 & \\
\hline
\end{tabular}

Nota: $\chi^{2}=$ Chi cuadrado; $R^{2}=$ Cuadrado de Nagelkerke; $B=$ Coeficiente de regresión; E.T.= Error estándar; Wald $=$ Prueba de Wald; $p=$ Probabilidad; $O R=$ Odd ratio; I.C. $=$ Intervalo de confianza al 95\%; ROD = Recuerdo de Objetos Detallados; $C C I=$ Capacidad Creativa de Imágenes

\section{Diferencias en CIM con altas y bajas puntuaciones en EP}

Los hallazgos que muestran la Tabla 5 y Figura 3 arrojan diferencias significativas de pequeña magnitud para las Imágenes Espaciales en Movimiento ( $d=.26$ ) y para la Capacidad Creativa de Imágenes ( $d=.32$ ), sugiriendo que los universitarios con bajas puntuaciones en EP puntúan significativamente más alto en ambas facetas de la $\mathrm{CIM}$ que sus iguales con altas puntuaciones en EP.

Tabla 5.Diferencias en CIM con altas y bajas puntuaciones en EP

\begin{tabular}{lcccccccccc}
\hline & \multicolumn{1}{c}{$\begin{array}{c}\text { Prueba de } \\
\text { Levene }\end{array}$} & \multicolumn{2}{c}{$\begin{array}{c}\text { Bajas } \\
\text { puntuaciones }\end{array}$} & \multicolumn{2}{c}{$\begin{array}{c}\text { Altas } \\
\text { puntuaciones }\end{array}$} & \multicolumn{5}{c}{$\begin{array}{c}\text { Significación } \\
\text { Estadística }\end{array}$} \\
\hline Dimensiones & $F$ & $p$ & $M$ & $D T$ & $M$ & $D T$ & $t$ & $g . l$ & $p$ & $d$ \\
\hline IEM & 6.29 & .012 & 6.12 & 2.83 & 5.42 & 2.54 & 2.68 & $\begin{array}{r}347.6 \\
2\end{array}$ & .008 & .26 \\
\hline IF & 4.85 & .028 & 7.88 & 3.14 & 8.21 & 3.45 & -1.06 & $\begin{array}{r}705.4 \\
7\end{array}$ & .288 & - \\
\hline ROD & 1.79 & .181 & 6.18 & 2.40 & 5.92 & 2.61 & 1.09 & 472 & .272 & - \\
\hline CCI & .36 & .549 & 6.66 & 2.46 & 5.91 & 2.31 & 3.35 & 472 & .001 & .32 \\
\hline $\begin{array}{l}\text { Total } \\
\text { VVIQ-RV- }\end{array}$ & .01 & .926 & 26.86 & 7.72 & 25.48 & 7.27 & 1.96 & 472 & .051 & - \\
12 & & & & & & & & & & \\
\hline
\end{tabular}

*Nota: IEM = Imágenes Espaciales en Movimiento; IF = Imágenes Familiares; ROD = Recuerdo de Objetos Detallados; CCI = Capacidad Creativa de Imágenes 
Figura 3. Diferencias en CIM en universitarios con altas y bajas puntuaciones en $P P^{\star}{ }^{*} p<.05,{ }^{\star \star} p<.01,{ }^{* \star *} p<.001$
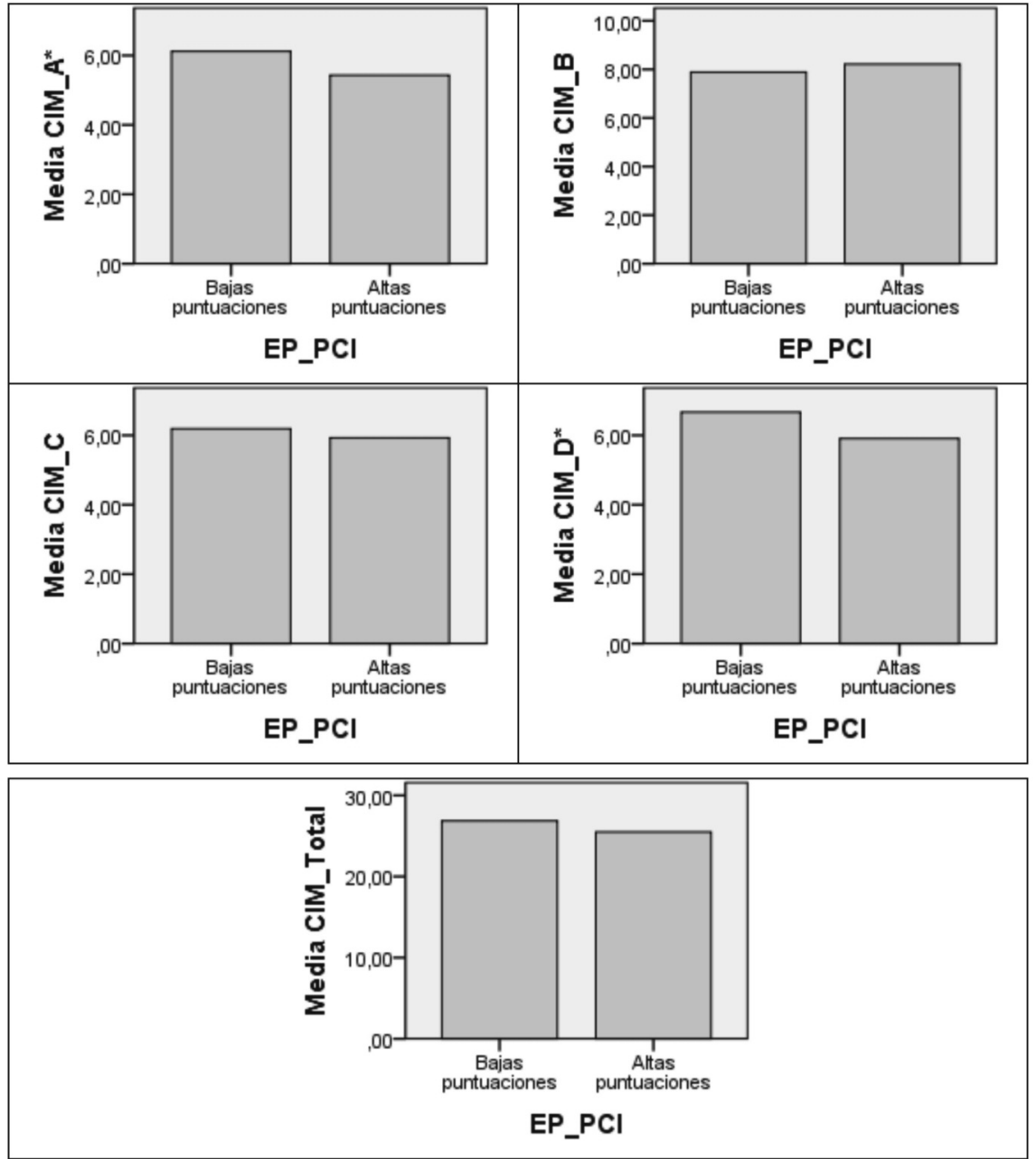

\section{Regresión logística binaria para la probabilidad de presentar alta puntuación EP en función de Imágenes Espaciales en Movimiento y Capacidad Creativa de Imágenes}

Los resultados observados en la Tabla 6 permiten realizar una estimación correcta del $62.4 \%$ de los casos $\left(\chi^{2}=7.43 ; p=<.05\right)$ para las Imágenes Espaciales en Movimiento y del $61.6 \%$ de los casos $\left(\chi^{2}=32.10 ; p=<.05\right)$ para la Capacidad Creativa de Imágenes. Asimismo, el valor de ajuste de los modelos ( $R^{2}$ Nagelkerke) comprende entre .02 para las Imágenes Espaciales en Movimiento y .03 para la Capacidad Creativa de Imágenes.

Los valores de la odd ratio $(O R)$ fueron $<1$ sugiriendo que conforme aumenta la puntuación en las Imágenes Espaciales en Movimiento y la Capacidad Creativa de Imágenes disminuye la probabilidad de presentar elevadas puntuaciones en los EP, con valores de .90 para Imágenes Espaciales en Movimiento y .87 para Capacidad Creativa de Imágenes. 


\section{RUMIAS PERFECCIONISTAS EN FUNCIÓN DE LA VIVEZA DE IMÁGENES MENTALES VISUALES}

Tabla 6. Regresión logística binaria para la probabilidad de presentar alto EP en función de las variables Imágenes Espaciales en Movimiento y Capacidad Creativa de Imágenes

\begin{tabular}{|c|c|c|c|c|c|c|c|c|c|}
\hline Variable & & $\chi^{2}$ & $R^{2}$ & $B$ & E.T. & Wald & $p$ & $O R$ & $\begin{array}{l}I . C . \\
95 \%\end{array}$ \\
\hline \multirow[t]{2}{*}{ IEM } & $\begin{array}{l}\text { Clasificados } \\
\text { correc.: } \\
62.4 \%\end{array}$ & 7.43 & .02 & $\begin{array}{l}- \\
.0 \\
9\end{array}$ & $\begin{array}{l}.0 \\
3\end{array}$ & 7.37 & .007 & .90 & \multirow[t]{2}{*}{$.84-.97$} \\
\hline & Constante & & & 1.04 & $\begin{array}{r}.2 \\
2\end{array}$ & $\begin{array}{r}21.1 \\
9\end{array}$ & $\begin{array}{r}<.0 \\
01\end{array}$ & 2.83 & \\
\hline \multirow[t]{2}{*}{$\mathrm{CCI}$} & $\begin{array}{l}\text { Clasificados } \\
\text { correc.: } \\
61.6 \%\end{array}$ & 11.05 & .03 & $\begin{array}{l}- \\
.1 \\
3\end{array}$ & $\begin{array}{r}.0 \\
4\end{array}$ & $\begin{array}{r}10.7 \\
5\end{array}$ & .001 & .87 & \multirow[t]{2}{*}{$.81-.95$} \\
\hline & Constante & & & 1.31 & $\begin{array}{l}.2 \\
7\end{array}$ & $\begin{array}{r}23.3 \\
8\end{array}$ & $\begin{array}{r}<.0 \\
01\end{array}$ & 3.74 & \\
\hline
\end{tabular}

Nota: $\chi^{2}=$ Chi cuadrado; $R^{2}=$ Cuadrado de Nagelkerke; $B=$ Coeficiente de regresión; E.T. $=$ Error estándar; Wald $=$ Prueba de Wald; $p=$ Probabilidad; $O R=$ Odd ratio; $I . C .=$ Intervalo de confianza al 95\%; IEM = Imágenes Espaciales en Movimiento; $\mathrm{CCI}=$ Capacidad Creativa de Imágenes

\section{DISCUSIÓN}

El objetivo del presente estudio era observar si existen diferencias estadísticamente significativas en los distintos factores del PCI y las dimensiones del VVIQ-RV-12, así como analizar la probabilidad de presentar PP, DP y EP en función de los distintos factores del VVIQ-RV-12.

Los resultados hallados desde este estudio, muestran desde los EP y las DP, que los universitarios con bajas puntuaciones en EP y DP puntúan significativamente más alto en Imágenes Espaciales en Movimiento y Capacidad Creativa de Imágenes que sus iguales con altas puntuaciones en EP y DP. El estudio de la relación entre los PAP y la CIM es muy limitado. Sin embargo, recientemente, el estudio de Aparicio-Flores (2020), con 419 futuros docentes, el cual halló tres perfiles con distinta intensidad de PAP, conformando un grupo de altos PAP, moderados PAP y bajos PAP, mostró que el perfil con bajos PAP puntuó más alto tanto en Imágenes Espaciales en Movimiento, como en Capacidad Creativa de Imágenes y el total del VVIQ-RV-12 que los perfiles con moderados y altos PAP, sin diferencias en las demás dimensiones del VVIQ-RV-12. El estudio detalló que tanto la Imágenes Espaciales en Movimiento como la Capacidad Creativa de Imágenes son factores que necesitan de una habilidad más creativa, mientras que Imágenes Familiares y Recuerdo de Objetos Detallados miden mayormente la vivacidad de la imagen donde entra en juego la memoria, y en menor medida el rasgo creativo, el cual puede verse declinado (Baas et al., 2014) debido a las consecuencias del estrés (Martha-Durán, 2010) que pueden desencadenar los PAP.

No obstante, Ios hallazgos encontrados con respecto a los PP muestran que aquellos participantes con altas puntuaciones en PP puntúan significativamente más alto tanto en Imágenes Espaciales en Movimiento como en Recuerdo de Objetos Detallados que los universitarios con bajas puntuaciones en el primer factor del PCI. Y, asimismo, que a medida que aumenta la puntuación en Imágenes Espaciales en Movimiento y Recuerdo de Objetos Detallados aumenta la posibilidad de presentar elevadas puntuaciones en PP. En este sentido, cabe destacar diversos aspectos, detallados en el estudio de Aparicio-Flores, Esteve-Faubel et al. (2020), el cual mostró correlaciones positivas y significativas entre las Imágenes Espaciales en Movimiento y las PP y el Recuerdo de Objetos Detallados y las PP. Por una parte, se debe tener en cuenta que las PP, medidas desde el rasgo perfeccionista, son la parte más insana del perfeccionismo por su vínculo con variables de carácter negativo (Chemisquy, 2018; Gonzálvez, et al. 2020), y se conocen como pensamientos reiterados basados en el miedo de no alcanzar un elevado rendimiento o por no ser bien valorado por los demás. Por otra parte, cabe destacar que las Imágenes 
Espaciales en Movimiento determinan la imagen nítida en movimiento, mientras que el Recuerdo de Objetos Detallados cumple con el recuerdo detallado de objetos que pueden ser estáticos 0 en movimiento (AparicioFlores, Esteve-Faubel et al., 2020). Es decir, a diferencia de las Imágenes Familiares y la Capacidad Creativa de Imágenes, que cuentan con una mayor libertad de espontaneidad, Imágenes Espaciales en Movimiento y Recuerdo de Objetos Detallados son dos factores que, con mayor creatividad o ejecución de la memoria, cumplen con un alto grado de detalle para precisar nítidamente todos los elementos de la imagen mental. En este sentido, y aunque es necesario contar con un mayor número de estudios que determine esta teoría, es posible que los sujetos con mayores PP se sientan más preocupados por obtener una interpretación más detallada de cualquier objeto.

Existen diversas limitaciones del estudio, no pudiendo generalizar los resultados a toda la diversidad cultural y etaria. Futuros estudios deberían replicar el trabajo con distintos países y distinta muestra adolescente y de edad adulta con un amplio abanico de estudios y profesiones con relación educativa, artística y no artística.

Sin embargo, y pese a las limitaciones observadas, este estudio muestra hallazgos novedosos en la viveza de imágenes mentales de los universitarios con baja y alta intensidad de PAP, aportando datos beneficiosos hacia el diseño de estrategias de organización mental (Dijkstra et al., 2017; Espada, et al., 2012; Mendez, et al, 2008 ), rendimiento, atención y memoria (Aparicio-Flores, Vicent et al., 2020; Pearson, 2014) que en ocasiones juegan malas pasadas en sujetos con altos niveles de PAP.

\section{CONCLUSIONES}

En conclusión, este estudio contribuye con la comunidad científica a observar el vínculo de los PAP y la CIM, aportando información al campo de la psicología, educación y arte, para diseñar estrategias de intervención y prevención de los PAP y sus trastornos comórbidos.

\section{REFERENCIAS BIBLIOGRÁFICAS}

Aparicio-Flores, M.P. (2020). Perfiles de pensamientos automáticos perfeccionistas y diferencias de la viveza de imágenes mentales. European Journal of Child Development, Education and Psychopathology, 8(1), 73-84. https://doi.org/10.30552/ejpad.v8i1.133

Aparicio-Flores, M.P., Esteve-Faubel, J.M., Vicent-Juan, M., y Sanmartín-López, R. (2020). Propiedades psicométricas del Vividness of Visual Imagery Questionnaire en España [Psychometric Properties of the Vividness of Visual Imagery Questionnaire in Spain]. Revista en Psicología Latinoamericana, 38(2), 1-14. https://doi.org/10.12804/revistas.urosario.edu.co/apl/a.7482

Aparicio-Flores, M.P., Esteve-Faubel, J.M., Vicent, M., Gonzálvez, C., Sanmartín, R., y García-Fernández, J.M. (2021). Dispositional empathy and emotional intelligence in terms of perfectionistic automatic thoughts. The Spanish Journal of Psychology, 24, 1-10. https://doi.org/10.1017/SJP.2020.57

Aparicio-Flores, M.P., Vicent, M., Sanmartín, R., Gonzálvez, C., Freire-Andino, R.0., y García-Fernández, J.M. (2020). Psychometric properties of the Perfectionism Cognitions Inventory in Ecuador. International Journal of Environmental Research Public Health, 17(16), 5834. https://doi.org/10.3390/ijerph17165834

Babapour, K. J., Esmaeilpour, K. y Saeedi, D.S. (2015). The role of perfectionism in predicting feeling of cognitive, physical and social fatigue. Journal of Psychology, 19(2), 163-174.

Baas, M., Nevicka, B., y Ten-Velden, F.S. (2014). Specicfic Mindfulness skills differentially predict creative performance. Personality and Social Psychology, 40(9), 1092-1106.

https://doi.org/10.1177/014616721435813

Cohen, J. (1988). Statistical power analysis for the behavioral sciences. Hillsdale, NJ: Erlbaum.

Chemisquy, S. (2018). Revisión teórica sobre el perfil cognitivo del perfeccionismo desadaptativo. Revista de Investigación Apuntes Universitarios, 16-40. https://doi.org/10.17162/au.v8i1.177

Crãciun, B. y Holdevici, I. (2012). Cognitive-behavioural intervention in diminishing perfectionistic self-presen- 


\section{RUMIAS PERFECCIONISTAS EN FUNCIÓN DE LA VIVEZA DE IMÁGENES MENTALES VISUALES}

tation and depression. Procedia-Social and Behavioral Sciences, 78, 476-480. https://doi.org/10.1016/j.sbspro.2013.04.334

Damian, L. E., Stoeber, J., Negru, O. y B ban, A. (2017). Perfectionism and schoolvengagement: A three-wave longitudinal study. Personality and Individual Differences, 105, 179- 184. https://doi.org/10.1016/j.paid.2016.09.044

Dijkstra, N., Bosch, S.E., y Van Gerven, M.A.J. (2017). Vividness of visual imagery depends on the neural overlap with perception in visual areas. The Journal of Neuroscience, 37(5), 1367-1373. https://doi.org/10.1523/JNEUROSCI.3022-16.2016

Espada, J.P., Griffin, K. W., Pereira, J.R., Orgilés, M. y Garcia-Fernandez, J.M. (2012). Component Analysis of a School-Based Substance Use Prevention Program in Spain: Contributions of Problem Solving and Social Skills Training Content. Prevention Science, 13, 86-95. D0I: 10.1007/S11121-011-0249-Y

Esteve-Faubel, J.M., Aparicio-Flores, M.P., Vicent, M., Gonzálvez, C., Sanmartín, R., y García-Fernández, J.M. (2020). Validation of Spanish version of the Perfectionism Cognitions Inventory: Profiles of automatic perfectionism thoughts and their associations with social anxiety. Professional Psychology: Research and Practice, 51(3), 268-277. https://doi.org/10.1037/pro0000290

Flett, G. L., Coulter, L. M., Hewitt, P. L. y Nepon, T. (2011). Perfectionism, rumination, worry, and depressive symptoms in early adolescents. Canadian Journal of School Psychology, 26 (3), 159-176.

Flett, G. L., Hewitt, P. L., Blankstein, K. R. y Gray, L. (1998). Psychological distress and the frequency of perfectionistic thinking. Journal of Personality and Social Psychology, 75(5), 1363-1381. https://doi.org/10.1037/0022-3514.75.5.1363

Flett, G. L., Nepon, T., Hewitt, P. L. y Fitzgerald, K. (2016). Perfectionism, components of stress reactivity, and depressive symptoms. Journal of Psychopathology and Behavioral Assessment, 38, 645-654. https://doi.org/10.1007/s10862-016-9554-x

Gonzalvez, C., Inglés, C. J., Sanmartin, R., Vicent,M., Calderón, C.M. y Garcia-Fernandez, J. M. (2020). Testing factorial invariance and latent means differences of the school refusal assessment scale-revised in Ecuadorian adolescents. Current Psychology, 39, 1715-1724. https://doi.org/10.1007/s12144-018-9871-1

Hewitt, P. L. y Genest, M. (1990). The ideal self: schematic processing of perfectionistic content in dysphoric university students. Journal of Personality and Social Psychology, 59(4), 802-808. https://doi.org/10.1037/0022-3514.59.4.802

Mahmoodi-Shahrebabaki, M. (2017). The effect of perfectionism on burnout among English language teachers: the mediating role of anxiety. Teachers and teaching, 23(1), 91-105. https://doi.org/10.1080/13540602.2016.1203776

Martha-Durán, M. (2010). Bienestar psicológico: el estrés y la calidad de vida en el contexto laboral. Revista Nacional de Administración, 1(1), 71-84.

Marks, F.M. (1973). Visual imagery differences in the recall of pictures. British Journal of Psychology, 64 (1), $17-$ 24. https://doi.org/10.1111/j.2044-8295.1973.tb01322.x

Mendez, F.X., Espada, J.P., Orgiles, M., Hidalgo, M.D. y Garcia-Fernandez, J. M. (2008). Psychometric properties and diagnostic ability of the separation anxiety scale for children (SASC). European Child \& Adolescent Psychiatry, 17, 365-372. D0I: 10.1007/S00787-008-0678-8

Nagelkerke, N.J.D. (1991). A note on a general definition of the coefficient of determination. Biometrika, 78(3), 691-692.

Pearson, J. (2014). New directions in mental-imagery research: the binocular-rivalry technique and decoding fmRl patterns. Association for Psychological Science, 23(3), 178-183. https://doi.org/10.1177/0963721414532287

Shih, S. S. (2011). Perfectionism, implicit theories of intelligence, and Taiwanese eighthgrade students' academic engagement. The Journal of Educational Research, 104(2), 131-142.

https://doi.org/10.1080/00220670903570368 
Smith, M. M., Saklofske, D. H., Yan, G. y Sherry, S. B. (2016). A person-centered perspective on multidimensional perfectionism in canadian and chinese university students: a multigroup latent profile analysis. Journal of Multicultural Counseling and Deveolpment, 44, 135-151. https://doi.org/10.1002/jmcd.12042

Tapia-Pavón, A. (2012). Predisposiciones que influyen en el rendimiento académico. Online

Wigert, B., Reiter-Palmon, R., Kaufman, J. C., y Silvia, P. J. (2012). Perfectionism: the good, the bad, and the creative. Journal of Research in Personality, 46(6), 775-559. https://doi.org/10.1016/j.jp.2012.08.007 
